\title{
A contemporaneidade da arte moderna e a exigência da filosofia ensaística em Walter Benjamin
}

Pedro Duarte*

\begin{abstract}
RESUMO: O artigo caracteriza a prática da filosofia de Walter Benjamin através de seus encontros com a arte. Busca, a partir daí, extrair o sentido já contemporâneo da arte moderna, ou seja, antes mesmo que cronologicamente se iniciasse o que se convencionou chamar de arte contemporânea. Por fim, o artigo destaca o ensaio como forma filosófica atrelada à arte.
\end{abstract}

PALAVRAS-CHAVE: Benjamin, arte, contemporaneidade, ensaio

ABSTRACT: The article describes the practice of Walter Benjamin's philosophy through its encounters with art. It aims, using this as a starting point, to extract the already contemporary meaning of modern art, that is, even before what is commonly and chronologically called contemporary art. Finally, the article highlights the essay as a philosophical form linked to art.

KEYWORDS: Benjamin, art, contemporaneity, essay

\footnotetext{
*Pedro Duarte é doutor e mestre em Filosofia pela PUC-Rio, onde atualmente é professor na graduação, na pós-graduação e na especialização em Arte e Filosofia. Foi professor visitante nas universidades Brown (EUA) e Södertörns (Suécia). É autor dos livros Estio do tempo: Romantismo e Estética Moderna (Zahar) e A Palavra Modernista: vanguarda e manifesto (Casa da Palavra), além de diversos artigos publicados em periódicos acadêmicos e na grande mídia. E-mail: p.d.andrade@gmail.com
} 
Walter Benjamin pensou tudo o que pensou através da arte. Tome-se, a título de exemplo, a questão da história. Sua caraterização pelo crítico foi feita a partir do quadro Angelus Novus, do pintor Paul Klee. De costas para o futuro e olhando o passado, o anjo da história, segundo Benjamin, jamais enxerga, com os seus olhos escancarados, alguma cadeia de acontecimentos coerente. Ruínas que crescem até o céu são os objetos de sua visão catastrófica. Ele até gostaria de juntar tais fragmentos dispersos. Só que suas asas abertas não permitem, pois sopra um vento da tempestade do progresso, que o empurra para o futuro, sem deixar ele se deter. Benjamin formula, nesta passagem de suas teses sobre o conceito de história, sua dura crítica ao progresso. Ideologicamente, ele serviria para justificar a visão política obtusa até do nazismo. Já o anjo da história - sobre o qual Benjamin escreve em 1940 - enxerga que o progresso da civilização moderna ocidental jamais foi cumprido sem que, ao mesmo tempo, trouxesse a barbárie. (BENJAMIN, 1994, p. 226)

Este olhar do anjo seria, em um sentido bastante específico, melancólico. Tanto que Benjamin também viu-se atraído, quando escreveu acerca do drama barroco alemão em 1924, pela muito conhecida gravura de Albrecht Dürer, feita em 1514, e cujo título é precisamente Melancolia I. Não se tratava exatamente da abordagem de Freud sobre o assunto, que designava a perda narcísica pela qual o sujeito declara-se desprovido de entusiasmo com a vida e sem capacidades. No entanto, o que a gravura de Dürer expõe é que, para o melancólico, os objetos desse mundo perderam o seu valor já conhecido de antemão, ficando espalhados pelo chão diante de um homem que, ao invés de empregar suas mãos para pegá-los e manuseá-los, apenas as faz de apoio para sua própria cabeça. Em outras palavras, as coisas, para o melancólico, abandonaram o seu caráter utilitário, deixam de servir para o que quer que seja. Tornam-se, por um outro lado, um objeto de ruminação, de meditação, de pensamento. (BENJAMIN, 1988, p. 161-180)

Entretanto, tal melancolia, que a filosofia aristotélica antiga chegou a considerar o humor filosófico por excelência, trazia para Benjamin um enorme perigo: a apatia. Ele escapou de tal perigo por duas vias. Primeiramente, pela vocação contra o conformismo, que aparece desde sua juventude. Depois, através de sua conhecida apropriação, ainda que peculiar, do pensamento de Marx, afinal, "os mortos não estarão em segurança se o inimigo vencer", escrevia Benjamin, "e esse inimigo não tem cessado de vencer". (BENJAMIN, 1994, p. 224-225) Daí vinha o patos de seu pensamento, cuja vibração pode ser sentida a cada tema tratado e, em 
certos casos, explicita-se até em seu caráter político propriamente dito, seja ele direto, como quando trata do Surrealismo por exemplo, ou indireto.

Se voltarmos à passagem em que Benjamin trata, ainda, de Paul Klee, podemos entender o que estaria em jogo para ele. Trata-se da percepção da quebra que o presente trazia em sua suposta continuidade com o patrimônio cultural do passado. Recusando a figura típica do homem "tradicional, solene, nobre, adornado com todas as oferendas do passado", Paul Klee dirigia-se "ao contemporâneo nu, deitado como um recém-nascido nas fraldas sujas de nossa época". (BENJAMIN, 1994, p. 224-225) Se as oferendas do passado transformaram-se muitas vezes em destroços bárbaros, como enxergou o anjo da história, caberia então ao artista mas também ao filósofo e ao cientista dirigirem-se ao presente sem empregá-las como se fossem suas vestimentas ainda. Nu, o homem contemporâneo poderia até estar com as fraldas sujas, posto que sua época sem dúvida é sombria. Tais fraldas, contudo, são as suas, as de hoje. Melhor do que as belas vestimentas de ontem. Nascia outra época.

Desiludido com o século em que viveu, Benjamin, entretanto, valorizava aquilo que, exatamente na desilusão, poderia ser descoberto. Livre dos pesos da tradição, quem sabe o homem contemporâneo encontrasse o passado de forma diferente? Paul Klee, de acordo com ele, fizera tal operação. Impulsionado pela pobreza de sua época, parte para frente, faz do pouco que tem o cerne para construir, para começar. Benjamin o colocava entre aqueles homens que queriam suas pranchetas, pois seu desejo era o de construção. Ruínas, para eles e para o próprio Benjamin, tinham valor não só pela destruição em si mesma, e sim porque, entre elas, seria possível ver caminhos por toda parte. Desilusão com a sua época e fidelidade a ela estariam juntas. Iconoclasta, Benjamin propõe, então, o que chama de barbárie positiva. (BENJAMIN, 1994, p. 115-116)

Nova, esta barbárie, ao contrário da que imaginamos tradicionalmente, concebe a destruição como simples confissão de que a época contemporânea jamais foi capaz de experimentar propriamente os valores do passado, ainda que os continuasse perpetuando hipocritamente. Reconhecer essa defasagem seria prova de honradez. Mais ainda, seria o primeiro passo daqueles "homens que fizeram do novo uma coisa essencialmente sua, com lucidez e capacidade de renúncia". (BENJAMIN, 1994, p. 119) Esse seria o diagnóstico de Benjamin sobre sua época. Eram algumas das "mais terríveis experiências da história" que estavam em jogo, por 
exemplo, com a Primeira Guerra Mundial, entre 1914 e 1918. Sinal disso é que seus combatentes, em geral, voltavam do campo de batalhas sem ter o que contar. Estavam pobres em experiências comunicáveis. Preferiam o silêncio à fala.

Essa situação exibia o contexto mais amplo no qual a cultura moderna como um todo ingressava: a guerra de trincheiras tornava-se a forma de experimentar a estratégia, a inflação virou o modo de experimentar a economia, a fome transformou-se na maneira de experimentar o corpo, os governantes eram o jeito de experimentar a moral. Em uma muito bela e igualmente conhecida passagem, Benjamin concluiu que "uma geração que ainda fora à escola num bonde puxado por cavalos viu-se abandonada, sem teto, numa paisagem diferente em tudo, exceto nas nuvens, e em cujo centro, num campo de forças de correntes e explosões destruidoras, estava o frágil e minúsculo corpo humano". (BENJAMIN, 1994, p. 115)

Escrevendo quase cem anos atrás, Benjamin enxergava o fenômeno que, hoje em dia, tornou-se um chavão sobre a época na qual vivemos. Enquanto antes a passagem da experiência de geração em geração era muito serena e segura, a época moderna a tornou altamente problemática, por conta de suas mudanças que não cessam nunca, junto com um desenvolvimento tecnológico sem precedentes. Essa aceleração do tempo histórico, cada vez mais veloz, fez a experiência dos antepassados ter um valor decrescente para os contemporâneos, pois seu mundo já era outro. Era a continuidade da tradição estética que estava comprometida sem os amparos da tradição, ou seja, daquele enquadramento prévio de significado colado ao passado. Ficava destituída a autoridade da velhice, que tradicionalmente era transmitida de forma concisa pelos provérbios ou de forma prolixa pelas narrativas. Era assim que, antigamente, transpunha-se a diferença geracional entre pais e filhos. Já agora, o que caracteriza o presente é a dificuldade de encontrar palavras tão duráveis que possam ser transmitidas "como um anel, de geração em geração". (BENJAMIN, 1994, p. 114)

Nesse contexto, é claro que as guerras eram apenas os eventos extremos através dos quais a condição mais geral dos problemas da cultura moderna seria expressa. Essa condição é o que Benjamin de fato tem em vista. Ela é caracterizada pelo esvaecimento da tradição precedente - como já sugerimos. Este fenômeno foi estudado por Benjamin especificamente no que concerne a arte, através do famoso diagnóstico sobre a perda da aura das obras. Tal perda ficaria patente pela desvalorização daquele "aqui e agora" que garantia à obra original a sua 
autenticidade. Empiricamente, a obra de arte antiga apenas habitava o espaço específico em que estava (um aqui) e aquele tempo (um agora). Tanto a fotografia quanto o cinema são as formas de arte emblemáticas da era moderna porque abandonam essa aura. Reprodutíveis tecnicamente por definição, ambas só têm cópias, nunca originais (estes são o negativo da obra). Enquanto objetos, podem estar em vários espaços e tempos empíricos distintos. Não há, como se sabe, o filme autêntico diferente de suas cópias espalhadas por aí, pois sumiu o traço distintivo do primeiro original, que ainda existia com a pintura tradicional, por exemplo. Rompia-se o testemunho histórico que a obra antiga concedia, uma vez que a sua autenticidade era a quintessência do que foi transmitido pela tradição; desaparece a autoridade da coisa original. (BENJAMIN, 1994, p. 168)

Enganam-se, entretanto, aqueles que compreendem o diagnóstico de fim da aura como simples denúncia da situação deletéria da arte atual. Nostalgia é algo distante do tom de Benjamin ao falar do assunto. Sem dúvida, existe perigo em tal estado de coisas, porque a arte deixou de estar atrelada aos cultos teológicos, como era no passado. Neste contexto, sua transformação em esteticismo espetacularizante é fácil, como provaram as práticas fascistas. Benjamin, porém, apostava ser possível também a positiva politização da estética, talvez pelo comunismo. Sem decidir sobre o acerto da (questionável) aposta histórica específica, destaca-se aqui a atenção para o que se ganha com a perda da aura. Libera-se, segundo Benjamin, o potencial político de difusão da arte. Não só: a câmera tecnológica - fotográfica e cinematográfica - abre possibilidades perceptivas que o olho natural humano não tem, alargando o seu contato com tudo o que é. Inspirado em Freud, Benjamin arrisca dizer que, entre essas possibilidades, estaria a descoberta da dimensão do olhar que foge à consciência. Inconsciente óptico foi como ele a chamou. (BENJAMIN, 1994, p. 168) Nenhum tipo de formação e educação que tentasse desbravar o que a modernidade da arte teria a oferecer poderia desprezar tais conquistas da fotografia e do cinema.

Mudando de âmbito, outra expressão contundente do declínio da tradição esteve na perda da transmissão oral de experiências. Narrar tornou-se, para o homem moderno, empreitada difícil, se é que ainda possível. Daí vem o desaparecimento das duas figuras que culturalmente simbolizavam essa atividade: o marinheiro comerciante e o camponês sedentário. Eles sabiam como contar suas estórias: o primeiro transmitia sua experiência das terras distantes para onde viajara, enquanto o segundo passava sua experiência das épocas distantes 
em que vivera. Sem as antigas distâncias de espaço e tempo, sempre encurtadas pela era moderna em seu furor tecnológico e comunicacional, a capacidade de contar, pela qual tais distâncias eram transpostas, ficou atrofiada. Todo o fundo de aconselhamento para a vida social que continham essas estórias perde seu sentido. Dar conselhos tornou-se antiquado, explica Benjamin, pois tal gesto consistia em sugerir continuidade a partir da experiência narrada. Intercambiada de pessoa a pessoa, de boca em boca, a experiência era compartilhada e garantida, coletivamente, pelas sociedades artesanais. Industrializado, o capitalismo tornou o trabalho entrecortado e alienado. É a dimensão privada que ganha espaço. Individualmente, através de vivências apartadas da existência em comum com outros homens, a sabedoria abandonava sua forma clássica, esta dimensão épica da verdade que, como Benjamin dizia, estava em extinção.

No entanto, a experiência, se deixa de ser espontaneamente partilhada no bojo da tradição, pode ainda ser construída artificialmente. Sem a oralidade, a escrita configura- se, agora, como seu espaço próprio. Eis porque a era moderna testemunha o nascimento do romance, que, ao contrário da narrativa antiga, é transmitido por escrito. Mais ainda: é criado pelo indivíduo isolado e se destina a um outro indivíduo isolado. Segregado, o romancista escreve sozinho seu texto, que depois será lido - não em grupo - por alguém sentado, só, em sua poltrona. Foi com a invenção da imprensa, então, que a difusão do romance tornou-se possível. Longe de alterar só a forma exterior pela qual as estórias eram propagadas, tal contexto alterou seus conteúdos. Se a memória da narrativa antiga dedicava-se a "muitos fatos difusos", o romance fala de "um herói, uma peregrinação, um combate." (BENJAMIN, 1994, p. 211) Percebe-se a ênfase de Benjamin: antigamente o "muitos" coletivo, e já agora o "um" individual. Para ele, Mnemosyne, a deusa grega da reminiscência, divide-se em duas possibilidades: a memória da narrativa antiga e a rememoração do romance moderno. Enquanto aquela era extensiva, atingindo o coletivo social, esta opera por aprofundamento individual, às vezes simplesmente psicológico.

Liquidada a forma antiga das narrativas, os romances são a audaciosa pretensão de construção formal da experiência na época moderna. São o esforço por dar sentido à vida quando este parece ter sumido. Benjamin segue, aqui, várias teses de Georg Lukács em sua muito conhecida teoria do romance, onde ele já observava que esse gênero é "a tentativa desesperada, puramente artística, de produzir pelos meios da composição, com organização e estrutura, uma unidade que não é mais dada de maneira espontânea". (LUKÁCS, 2000, p. 
54) É preciso acrescentar que, para Benjamin, a unidade que aí se tenta produzir é menos entre as pessoas, dispersas pelo mundo moderno fragmentado, do que de cada um com a sua própria vida diante da morte. Sem tradição e autoridade que amparasse sua experiência, completamente desorientado, o homem poderia desesperar-se pela falta de sentido que a finitude encerra para sua vida. Do começo ao fim da existência, haveria, para além dos acontecimentos casuais, algum significado? Nos enredos romanescos iniciais, achamos o esforço de construção de coerência para a vida do herói que acompanhamos. Se a sua vida tivesse sentido, quem sabe a nossa poderia ter?

Sem acomodar-se na perda, tenta-se a construção, ainda que tivéssemos perdido a antiga capacidade de contar e escutar estórias. Informar virou a obsessão, orgulhosa de si própria, da época atual. Narrar, porém, está distante de ser só explicar, o que, aliás, precisa ser às vezes evitado para que a estória cative quem a ouve. Não é da quantidade de conhecimento que a experiência é feita, e sim da vida que os seus conteúdos ganham pela forma como são transmitidos. Só que Benjamin sabe que o exercício da forma foi quebrado. Como dizia, o homem atual só cultiva o que pode ser abreviado. Nenhum tipo de formação, contudo, pode ser feita apenas por siglas. Literariamente, o que tem valor não é o ponto onde chegamos, e sim o caminho que percorremos até ele. É onde vive o sentido, conforme aponta a anedota com a qual Benjamin abre o ensaio "Experiência e pobreza". Ela conta que um velho, exatamente na hora de sua morte, diz aos filhos que há um tesouro enterrado em seus vinhedos. Estes cavam até a exaustão, sem sucesso, já que não encontram o tesouro. Só que vem o outono, suas vinhas produzem mais do que todas as outras. Eles, então, entendem que o pai havia passado algo mais valioso do que qualquer tesouro material: sua experiência, que consistia em mostrar que era no trabalho que estava a felicidade. Foi percorrendo o caminho passo a passo que os filhos puderam compreender o seu sentido. Porém, foi a formação do homem através dessa transmissão da experiência que foi perdida na cultura moderna, segundo Benjamin.

Na certidão de nascimento desta época moderna, para Benjamin, estaria a poesia de Charles Baudelaire - autor com o qual possuía enorme afinidade. Embora admitisse que nela estaria "a última obra lírica a exercer influência no âmbito europeu", Benjamin completava que "não se pode refutar o fato de que alguns dentre os seus temas colocam em questão a possibilidade mesma de uma poesia lírica". (BENJAMIN, 1989, p. 143) É que essa poesia (lírica), de Baudelaire, já colocava sob suspeita a própria tradição (lírica). Ele também fazia parte, então, 
da transformação estrutural da experiência de que falou Benjamin. Modernidade, para o poeta, seria a construção de outras "correspondências" com o passado, diferentes das fixadas por toda a tradição anterior que caía por terra, inclusive nas transformações concretas das cidades. Era a alegoria que constituía a estratégia fundamental da poética de Baudelaire, no século XIX, pois só com ela se poderia ainda construir algum tipo de experiência para o homem da modernidade.

Paris muda! mas nada em minha nostalgia

Mudou! novos palácios, andaimes, lajedos,

Velhos subúrbios, tudo em mim é alegoria,

E essas lembranças pesam mais do que rochedos.

(BAUDELAIRE, 1985, p. 327)

O dândi e o flâneur eram figuras que, pela poesia de Baudelaire, indicavam uma interessante modernização. Dentro e fora da multidão, o flâneur caminha em meio a ela sem, contudo, seguir seu ritmo apressado e interessado. Mergulha nas ruas e na agitação das grandes cidades, ainda que se coloque ali de forma diferente daquela dos transeuntes cotidianos. É a ociosidade de seu andar que o distingue, posto que ela protesta "contra a divisão do trabalho que transforma as pessoas em especialistas", e ainda também contra o industrialismo. Benjamin comenta que, por volta de 1840, chegava a ser de bom tom levar tartarugas para passear dentro das galerias parisienses... "De bom grado, o flâneur deixava que elas the prescrevessem o ritmo de caminhar," e na verdade, "se o tivessem seguido, o progresso deveria ter aprendido esse passo". (BENJAMIN, 1989, p. 51) Novamente, como no caso do anjo da história, estamos diante da dura crítica de Benjamin ao progresso. Novamente, estamos diante, com o flâneur, de uma figura à contracorrente e que, assim, pode ver o mundo por outro viés. Era o que queria Benjamin.

\footnotetext{
“Nos degraus da Torre Eiffel, varridos pelo vento, ou melhor ainda, nas pernas de aço de uma pont transbordeur, confrontamo-nos com a experiência estética fundamental da arquitetura de hoje: através da fina rede de ferro estendida no ar, passa o fluxo das coisas - navios, mar, casas, mastros, paisagem, porto. Elas perdem sua forma delimitada: quando descemos, elas rodopiam umas nas outras, e simultaneamente se misturam". (Sigfried Giedion, Bauen in Frankreich, Leipzig-Berlim, p. 7). Assim também o historiador hoje tem que construir uma estrutura - filosófica - sutil, porém resistente, para capturar em sua rede os aspectos mais atuais do passado.
} 
No entanto, assim como as magníficas vistas das cidades oferecidas pelas novas construções de ferro (...) ficaram durante muito tempo reservadas exclusivamente aos operários e engenheiros, também o filósofo que deseja captar aqui suas primeiras visões deve ser um operário independente, livre de vertigens e, se necessário, solitário. (BENJAMIN, 2006, p. 501 [N 1a, 1])

Novas formas de pensar, portanto, eram procuradas por Benjamin para entrar em contato com suas questões sem a antiga fundamentação que falira. Nas artes, ele, tantas vezes, as encontrou. Mas só pôde fazê-lo porque já concebia também a própria filosofia, por sua vez, de um modo distinto do tradicional. Esta explicitaria a contemporaneidade de práticas artísticas de qualquer época, inclusive da sua. Segundo ele, o texto filosófico caracteriza-se pelo confronto, a cada vez, com a forma de apresentação, isto é, com sua própria forma de expressão. (BENJAMIN, 1988, p. 49) Esta não é somente problema da arte, como se à filosofia coubessem apenas os conteúdos. Também a filosofia se faz enquanto texto e, portanto, deve cuidar de "como" apresenta "o que" ela pensa. Longe de ser o apanágio que adorna aquilo que se diz, a apresentação decide o sentido do que vai dito, ou seja, sua verdade. Distanciando-se da tradição proveniente de Descartes, Benjamin não situava a verdade na representação mental subjetiva, e sim na apresentação material e concreta da forma do texto, que no caso da filosofia deveria ter uma sobriedade prosaica. (GAGNEBIN, 2005) Entende-se que a linguagem do texto filosófico, para Benjamin, não seja apenas o auxílio exterior para a expressão da verdade, pois esta não "voa de fora para dentro". Mergulhando no objeto é que se poderia pensá-lo porque "a relação entre o trabalho microscópico e a grandeza do todo plástico e intelectual demonstra que o conteúdo de verdade só pode ser captado pela mais exata das imersões nos pormenores do conteúdo material". (BENJAMIN, 1988, p. 51)

Era assim que, no século passado, Benjamin pretendia "salvar os fenômenos" através do pensamento teórico, seguindo e torcendo, ao mesmo tempo, o que já queria a filosofia de Platão. Isso tornou possível a ele pensar as práticas artísticas que eram suas contemporâneas, bem como outras mais antigas que adquiriam uma contemporaneidade através de sua interpretação. Foi junto com a arte, através dela e muitas vezes mesmo a violentando, que Benjamin construiu seu caminho teórico particular. Isso significa que a arte, em seu caso, não era somente um objeto de estudo exterior, mas sim um elemento em contato com o qual seu pensamento pôde vir a ser o que ele é. Entender o que pensa Benjamin é compreender 
o que ele pensou sobre Paul Klee ou Dürer, sobre Baudelaire, Proust ou Kafka, sobre Goethe, Hölderlin ou Brecht, sobre o Romantismo, o Barroco ou o Surrealismo, sobre cinema e fotografia. Para ficar somente em alguns exemplos. Isso evidencia que a contribuição da obra teórica de Walter Benjamin para se pensar práticas artísticas contemporâneas ainda hoje não reside apenas nas suas teses proféticas sobre o destino da estética do século XX que alcançariam o século XXI. Sua obra cunhou, além disso, um novo método (ou, seguindo a célebre fórmula, um desvio) pelo qual a própria filosofia descobria, através da sua prática específica como ensaio, a contemporaneidade das obras de arte que analisava.

Filosofia e arte, separadas pela querela que já Platão considerava ser bem antiga, eram aproximadas por Benjamin. Não se tratava, porém, de apaziguar o conflito, já que possivelmente a força de cada elemento - da filosofia e da arte - aumenta quando posta dentro deste embate. Só é equívoco colocá-las numa disputa por prioridade ontológica e corporativa, por exemplo. Mesmo porque, a arte, para Benjamin, deixa de ser o assunto sobre o qual a filosofia se debruça. Na medida em que é da alçada da filosofia enfrentar sua forma de expressão literária própria, então ela mesma possui certo caráter artístico. Importa também à filosofia a construção da escrita, de sua prosa específica, seja tratado medieval, seja ensaio moderno. Nessa construção crítica, aparecia uma aproximação dos âmbitos tradicionalmente postos em oposição absolutamente excludente - a filosofia e a arte. Benjamin, ao praticar a filosofia como arte da crítica, pôde então pensar as práticas artísticas em sua contemporaneidade própria, independentemente da cronologia que as organizaria por datas. O tempo da arte é outro. Logo, a sua contemporaneidade também é outra. Sempre outra.

\section{Referências}

BAUDELAIRE, Charles. As flores do mal. Rio de Janeiro: Nova Fronteira, 1985.

BENJAMIN, Walter. Livro das passagens. Belo Horizonte: Editora UFMG; São Paulo: Imprensa Oficial, 2006.

BENJAMIN, Walter. Sobre o conceito de história. In: Magia e técnica, arte e política - Obras escolhidas; v. 1. São Paulo: Brasiliense, 1994.

BENJAMIN, Walter. Experiência e pobreza. In: Magia e técnica, arte e política - Obras escolhidas; v. 1. São Paulo: Brasiliense, 1994.

BENJAMIN, Walter. A obra de arte na era de sua reprodutibilidade técnica. In: Magia e técnica, arte e política - Obras escolhidas; v. 1. São Paulo: Brasiliense, 1994. 
BENJAMIN, Walter. O narrador. In: Magia e técnica, arte e política - Obras escolhidas; v. 1. São Paulo: Brasiliense, 1994.

BENJAMIN, Walter. Sobre alguns temas em Baudelaire. In Obras escolhidas; v. 3. São Paulo: Brasiliense, 1989.

BENJAMIN, Walter. Paris do Segundo Império. In: Obras escolhidas; v. 3. São Paulo, Brasiliense, 1989.

BENJAMIN, Walter. Origem do drama barroco alemão. São Paulo: Brasiliense, 1988.

GAGNEBIN, Jeanne Marie. Do conceito de Darstellung em Walter Benjamin, ou verdade e beleza. Kriterion, Belo Horizonte, v. 46, n. 112, dez. 2005

LUKÁCS, Georg. A teoria do romance. São Paulo: Duas Cidades; Ed. 34, 2000. 